\title{
Cerebellar Artery
}

National Cancer Institute

\section{Source}

National Cancer Institute. Cerebellar Artery. NCI Thesaurus. Code C52845.

An artery that orig inates from the basilar artery and distributes blood to the cerebellum. 